\title{
Tecnologias Assistivas, Ensino de Frações e SURDEZ: OLHARES DE ACADÊMICOS DE UM CURSO DE LiCENCIATURA EM MATEMÁtica
}

\author{
Assistive TeCHNOLOGIES, FRACTION TEACHING AND DEAFNESS: \\ LOOKS OF ACADEMICS OF A COURSE OF DEGREE IN MATHEMATICS
}

DOI: http://dx.doi.org/10.23926/RPD.2526-2149.2019.v4.n2.p391-410.id450

\section{Larissa Leal Scapin \\ Graduação em andamento em Licenciatura em \\ Matemática (UNIOESTE) \\ larissalara94@hotmail.com}

\section{Vanessa Lucena Camargo de Almeida} Klaus

Doutorado em andamento em Educação em Ciências e Educação Matemática (UNIOESTE)

Docente (UNIOESTE) vanessa.almeida3@unioeste. br

\section{Andreia Nakamura Bondezan \\ Doutora em Educação \\ (UEM)}

Professora do Programa de

Pós-Graduação em

Sociedade, Cultura e

Fronteira (UNIOESTE)

andreiabondezan76@gmail.c om

\section{Marcos Lübeck \\ Doutor em Educação \\ Matemática (UNESP/Rio \\ Claro) \\ Professor do Programa de \\ Pós-Graduação em Ensino \\ (UNIOESTE) \\ marcos.lubeck@unioeste.br}

Resumo: Neste artigo apresentamos uma experiência investigativa com tecnologias assistivas e surdez, aplicada no Curso de Licenciatura em Matemática de uma Universidade Pública de Foz do Iguaçu/PR. Com base num Estudo de Caso e na Análise de Conteúdo, realizamos uma revisão bibliográfica sobre educação especial, inclusão escolar, formação inicial de professores e tecnologias assistivas, bem como implementamos uma proposta educativa com os acadêmicos da referida instituição, com o objetivo de trazer olhares desses futuros professores com relação ao uso de algumas tecnologias assistivas no ensino de frações, considerando as particularidades da surdez. Os resultados mostram que houve avanços no processo de ensino e aprendizagem deste conteúdo e sobre a temática da inclusão escolar na visão dos acadêmicos, e os apontamentos apresentados por eles nas descrições das aulas e a análise dos seus registros escritos permitem dizer que a proposta, a depender da criatividade e planejamento do professor e da consideração que o mesmo faz do contexto em que os alunos, ouvintes e surdos, se encontram inseridos, pode ser inclusiva. E as reflexões acerca dessa prática de ensino nos levam a concluir que houve uma contribuição significativa para a formação inicial dos acadêmicos do curso de Licenciatura em Matemática.

Palavras-chave: Ensino de Matemática. Tecnologias Assistivas. Surdez. Formação Inicial de Professores.

\begin{abstract}
In this paper we present an investigative experience with assistive technologies and deafness, applied in a Mathematics Degree Course at a Public University of Foz do Iguaçu/PR. Based on a Case Study and the Content Analysis, we conducted a bibliographic review on special education, scholar inclusion, initial teacher training and assistive technologies, as well implemented an educative proposal with the academics from that institution, with the objective of bringing looks of these future teachers regarding the use of some assistive technologies in teaching fractions, considering the particularities of deafness. The results show that there have been advances in the teaching and learning process of this content and on the theme of inclusion in the academics vision, and the notes presented by them in the classes descriptions and the analysis of their written records allow us to say that the proposal, depending on the creativity and planning of the teacher and his consideration of the context in which students, listeners and deaf people are inserted, can be inclusive. And the reflections about this teaching practice lead us to conclude that there was a significant contribution to the initial training of the undergraduate students in Mathematics.

Keywords: Mathematics Teaching; Assistive Technologies; Deafness; Initial Teacher Training.
\end{abstract}




\title{
1 INTRODUÇÃO
}

Cada dia mais, sentimos a necessidade de debater sobre a inclusão escolar, visto que hoje, nas salas de aula regulares, os alunos com deficiências estão presentes, quer seja em turmas do ensino básico e ou mesmo do ensino superior, o que permite aos professores, pais, equipe pedagógica e comunidade interessada, buscar alternativas de ascensão à uma educação de excelente qualidade, esta como direito de todas as pessoas.

Com isto, aventamos aqui parte de uma pesquisa realizada na Universidade Estadual do Oeste do Paraná (UNIOESTE), campus de Foz do Iguaçu/PR, a qual teve como objetivo investigar temáticas da inclusão escolar, das tecnologias assistivas e da surdez, com o propósito de propiciar contribuições para a formação inicial de professores em Matemática. Aliás, o histórico do curso de Licenciatura em Matemática da mencionada instituição mostra uma preocupação constante com a formação dos acadêmicos e profissionais da educação, como afirmam Lübeck, Klaus e Moura (2018, p. 77):

\begin{abstract}
Dentre as diversas situações que o curso tem se deparado ao longo destes vinte anos, e que encontram-se continuamente sob discussão e reflexão, estão as práticas educativas e de ensino que direcionam para uma formação docente de ótima qualidade, e que buscam oferecer as melhores condições possíveis aos acadêmicos, ainda durante o decorrer do seu processo de formação inicial, para que estes investiguem, conheçam e apreendam ações e posturas que propiciem adequadas atitudes e boas metodologias para lecionar Matemática, sobretudo, as harmonizadas com as atuais perspectivas da educação inclusiva.
\end{abstract}

A pesquisa envolveu, ainda, a implementação de uma proposta para o ensino de frações para alunos surdos, na turma de $3^{\circ}$ ano do curso de Licenciatura em Matemática da universidade. Disso, resultaram impressões dos acadêmicos a respeito de práticas de ensino por meio da utilização de tecnologias assistivas nas salas de aula de Matemática, tendo como problemática principal a seguinte: que olhares esses acadêmicos apresentam do uso de algumas tecnologias assistivas no ensino de frações para alunos surdos?

Para responder a este questionamento fizemos um levantamento bibliográfico do assunto tecnologias assistivas e a prática inclusiva nas aulas de Matemática e, por meio de um estudo de caso, investigamos a forma como esses alunos lidam, por exemplo, com problemas matemáticos adaptados, círculos fracionários e jogos, como o Dominó de Frações e a Trilha de Frações. Por fim, com base nas orientações da Análise de Conteúdo de Bardin (2011), analisamos os registros escritos dos acadêmicos e aplicamos um questionário avaliativo para sabermos as impressões da proposta de ensino sugerida, contribuindo, portanto, para a nossa análise e obtenção de resultados, que nos proporcionaram inferir e refletir a respeito da temática tecnologias assistivas no ensino de frações para alunos surdos a partir de olhares dos 
acadêmicos do $3^{\circ}$ ano do curso de Licenciatura em Matemática da UNIOESTE, campus de Foz do Iguaçu/PR.

\section{EducaÇÃo Especial, Inclusão Escolar E FormaÇão Docente: algumas REFLEXÕES}

Ao falarmos de educação, temos a consciência de que o ato de educar “[...] conduz a liberdade, combatendo a alienação dos homens através da compreensão do indivíduo como ser ele mesmo, desenvolvendo suas potencialidades, humanizando-se no exercício da responsabilidade que tem frente as mudanças sociais" (SCHRAM; CARVALHO, 2010, p. 14). Posto isto, "a educação, em sentido amplo, representa tudo aquilo que pode ser feito para desenvolver o ser humano e, no sentido estrito, representa a instrução e o desenvolvimento de competências e habilidades" (VIANNA, 2006, p. 130).

E, em relação à responsabilidade de educar, a Lei de Diretrizes e Bases da Educação Nacional (LDBEN), de 20 de dezembro de 1996, afirma que, no Art. 2ª a educação “[...] dever da família e do Estado, inspirada nos princípios de liberdade e nos ideais de solidariedade humana, tem por finalidade o pleno desenvolvimento do educando, seu preparo para o exercício da cidadania e sua qualificação para o trabalho" (BRASIL, 1996, p. 1).

Disto, entendemos que a família e a escola, conjuntamente, precisam trilhar caminhos pela busca da formação de indivíduos ativos, aptos a tomar decisões e transformar a sociedade. Cabe ressaltarmos sempre que cada indivíduo é único e possuidor de atributos, dificuldades e habilidades próprias. E alguns necessitam de atendimento, recursos assistivos, processos de ensino e aprendizagem, dentre outros, diferenciados, faces suas características.

No caso de alunos com necessidades educacionais especiais, a Educação Especial surgiu como uma modalidade específica, apresentada na LDBEN de 1996, que veio com o propósito de assegurar o acesso e os direitos desses alunos ao ensino regular da Educação Básica, onde está especificado, no Art. 58, que por educação especial entende-se “[...] para os efeitos desta Lei, a modalidade de educação escolar oferecida preferencialmente na rede regular de ensino, para educandos com deficiência, transtornos globais do desenvolvimento e altas habilidades ou superdotação" (BRASIL, 1996, p. 23).

Para a construção de uma sociedade inclusiva, é de fundamental importância que o Estado fortaleça a democracia e, nesse caminho, lute por um sistema político que atenda, de forma igualitária, dentre outras, as demandas sociais da população, como a educação inclusiva. Baquero (2008, p. 388) exemplifica, mencionando a necessidade de 
[...] possuir práticas políticas participativas na cultura política da cidadania, simultaneamente com a construção de uma rede institucional forte que regule a vida política e que se constitua no espaço por excelência da tomada de decisões. A questão subjacente a esta preocupação diz respeito ao poder dos cidadãos em desenhar as instituições que eles operam e não, simplesmente, reagir mais ou menos passivamente a situações dadas e impostas.

Historicamente, percebemos que falar de inclusão escolar é um tema complexo, pois como é afirmado nas Diretrizes Nacionais para a Educação Especial na Educação Básica (BRASIL, 2001, p. 22), observamos que:

Um longo caminho foi percorrido entre a exclusão e a inclusão escolar e social. Até recentemente, a teoria e a prática dominantes relativas ao atendimento às necessidades educacionais especiais de crianças, jovens e adultos, definiam a organização de escolas e de classes especiais, separando essa população dos demais alunos. Nem sempre, mas em muitos casos, a escola especial desenvolvia-se em regime residencial e, consequentemente, a criança, o adolescente e o jovem eram afastados da família e da sociedade. Esse procedimento conduzia, invariavelmente, a um aprofundamento maior do preconceito.

Neste seguimento, para o processo de inclusão escolar poder ocorrer, houve necessidade de mudanças, em especial na forma de compreender a pessoa com deficiência, pois além do preconceito, notamos a segregação, haja vista que muitos ainda o compreendiam como um ser incapaz de aprender, se desenvolver e participar ativamente da sociedade. Uma tentativa falha para alterar esse quadro foi o movimento de integração escolar, pois o mesmo mantinha a escola inalterada e o aluno deveria se adequar a ela, caracterizado inicialmente por uma preparação do aluno em classes especiais e, posteriormente, uma integração total em classes comuns (MENDES, 2002).

Sobre o aluno com deficiência ser integrado, em Brasil (2001, p. 23), vemos que:

$\mathrm{O}$ aluno, nesse processo, tinha que se adequar à escola, que se mantinha inalterada. A integração total na classe comum só era permitida para aqueles alunos que conseguissem acompanhar o currículo ali desenvolvido. Tal processo, no entanto, impedia que a maioria das crianças, jovens e adultos com necessidades especiais alcançassem os níveis mais elevados de ensino. Eles engrossavam, dessa forma, a lista dos excluídos do sistema educacional.

Após diversas mudanças, por meio de lutas sociais, especialmente em prol da inclusão de pessoas com deficiências no âmbito da educação escolar regular e no mercado de trabalho, diferentes documentos oficiais brasileiros foram promulgados, como a referida Lei de Diretrizes e Bases da Educação Nacional (1996); o Decreto $\mathrm{n}^{\circ}$ 5.626, de 22 de dezembro de 2005, que regulamenta a Lei $\mathrm{n}^{\circ} 10.436$ de 2002 dispõe sobre a Língua Brasileira de Sinais (Libras) e seu reconhecimento como língua materna (BRASIL, 2002); a Resolução ${ }^{\circ}$ 4, de outubro de 2009, que Institui as Diretrizes Operacionais para o Atendimento Educacional Especializado na Educação Básica, modalidade Educação Especial; a Lei Brasileira de Inclusão 
da pessoa com deficiência ${ }^{1}$ (BRASIL, 2015), e outras que asseguram direitos de cidadania para aqueles que estiveram à mercê de uma cultura excludente.

Hoje, apesar das dificuldades e do desafiante caminho a percorrer, as escolas têm recebido alguns recursos e profissionais especializados na Educação Especial, para que os trabalhos com pessoas com deficiência possam acontecer da melhor forma possível, mas ainda não é o suficiente para uma educação de qualidade para todos os alunos, sendo necessárias mudanças substanciais, como a redução do número de alunos por turma, a aquisição de materiais adaptados, uma formação continuada consistente, dentre outras.

Com relação aos serviços especializados oferecidos nas escolas do Paraná, por exemplo, o Departamento de Educação Básica (DEB), Paraná (2014, p. 2) nos diz que:

[...] em cumprimento aos preceitos legais e às recomendações de documentos nacionais e internacionais, que destacam diretrizes para a construção de espaços educacionais inclusivos, a oferta de serviços de apoio complementar e suplementar especializados, nas escolas da rede pública de ensino, para o público-alvo da Educação Especial, é acrescido do atendimento aos alunos com transtornos funcionais específicos, organizado na SRM, Professor de Apoio à Comunicação Alternativa (PAC), Professor de Apoio Educacional Especializado (PAEE) e Tradutor e Intérprete de LIBRAS (TILS), Guia Intérprete e Professor Itinerante.

De acordo com o DEB, o serviço oferecido aos alunos na classe comum é um modo de complemento e apoio para o desenvolvimento desses alunos. Além disto, nas escolas do Estado do Paraná também são ofertadas salas de recursos multifuncionais de acordo com as particularidades do aluno, sendo elas: Sala de Recursos Multifuncional (SRM) - Deficiência Intelectual (DI), Deficiência Físico Neuromotora (DFN), Transtorno Global do Desenvolvimento (TGD), Transtornos Funcionais Específicos (TFE); Sala de Recursos Multifuncional (SRM) - Deficiência Visual; Sala de Recurso Multifuncional (SRM) - Surdez; Sala de Recurso Multifuncional (SRM) - Altas Habilidades/Superdotação (AH/SD).

Em relação a deficiência auditiva, cabe destacarmos que, embora nas leis do Brasil este termo é utilizado como sinônimo de pessoa surda, Vigna (2010, p. 39) entende por deficiência auditiva a "redução ou ausência da capacidade de ouvir determinados sons em diferentes graus de intensidade". Ainda, nos diz que deficiência auditiva "[...] é o nome usado para indicar perda de audição ou diminuição na capacidade de escutar sons". Agora, como afirmam Bisol e Sperb (2010, p. 8), ser surdo “[...] é reconhecer-se por meio de uma identidade compartilhada por

\footnotetext{
${ }^{1} \mathrm{Ou}$, “"... (Estatuto da Pessoa com Deficiência), destinada a assegurar e a promover, em condições de igualdade, o exercício dos direitos e das liberdades fundamentais por pessoa com deficiência, visando à sua inclusão social e cidadania" (BRASIL, 2015, p. 1).
} 
pessoas que utilizam língua de sinais e não veem a si mesmas como sendo marcadas por uma perda".

As pessoas surdas, cada vez mais, se mostram ativas na sociedade, frequentando clubes, principalmente esportivos, são membros atuantes de associações, de grupos religiosos, conquistando espaço no mercado de trabalho. Essa participação no meio social e sua eficiência, não somente na comunidade surda, faz com que o surdo se torne o próprio divulgador das vitórias alcançadas pela sua comunidade. No entanto, há uma dificuldade na comunicação dos surdos com os ouvintes, visto que ainda existem barreiras no que diz respeito a importância dada a mesma, pois o ensino da Língua Brasileira de Sinais ainda é deixado de lado ou visto com muita superficialidade pelos entes governamentais. A presença do Tradutor Intérprete de Libras (TILS) ${ }^{2}$ é indispensável para a comunicação do surdo nos diferentes contextos, e este profissional na educação é denominado intérprete educacional.

Embora sua presença na escola do surdo seja essencial, Vigna (2010, p. 43) apresenta exemplos de alguns meios de comunicação que podem auxiliar no processo de comunicação entre surdos e ouvintes na ausência deste profissional, tais como: “[...] o TTD (telefone com teclado numérico e alfabético, no qual as mensagens são digitadas, permitindo o diálogo entre as pessoas que o possuem) contribuem muito para facilitar conversas a distância entre surdos, ou mesmo entre surdos e ouvintes". Atualmente, a pessoa surda pode contar com aplicativos desenvolvidos especialmente para facilitar sua comunicação, principalmente com os ouvintes, tais como o Prodeaf Móvel ${ }^{3}$ e Hand Talk App ${ }^{4}$. No entanto, mesmo com estes recursos, ainda pode haver perdas na compreensão das mensagens. E é de domínio público o quanto a comunidade surda já sofreu por causa disso.

No que diz respeito a língua de Sinais no Brasil, Santos (2009, p. 24) coloca que:

A proposta bilíngue-bicultural surgiu como uma resposta a todos esses males causados pelo oralismo. Aliada a Antropologia e a Linguística, o bilinguismo iniciou a trajetória da reconstrução educacional dos sujeitos surdos. Nessa perspectiva, a língua materna das pessoas surdas passa a ser considerada como a primeira língua e o português (Brasil), como a segunda.

Todavia, ainda que o aluno surdo tenha direitos garantidos e o apoio do intérprete na sala de aula, muitas vezes, é preciso batalhar para que os mesmos sejam concretizados. Também é preciso programas de capacitação pedagógica para o professor lidar com as diferenças em sala

\footnotetext{
2 "Art. $2^{\circ} . \mathrm{O}$ tradutor e intérprete terá competência para realizar interpretação das 2 (duas) línguas de maneira simultânea ou consecutiva e proficiência em tradução e interpretação da Libras e da Língua Portuguesa" (BRASIL, 2010).

${ }^{3}$ Maiores informações em: http://prodeaf.net/pt-br/prodeaf-movel. Acessado em: 06 mai. 2019.

${ }^{4}$ Maiores informações em: https://www.handtalk.me/app. Acessado em: 06 mai. 2019.
} 
de aula. Por isto, ao pensarmos em caminhos para a inclusão dos alunos surdos no universo das salas de aulas de Matemática, Damázio (2007, p. 10) menciona que:

A inclusão do aluno com surdez deve acontecer desde a educação infantil até a educação superior, garantindo-lhe, desde cedo, utilizar os recursos de que necessita para superar as barreiras no processo educacional e usufruir seus direitos escolares, exercendo sua cidadania, de acordo com os princípios constitucionais do nosso país.

Para tanto, o respectivo pesquisador enfatiza ser necessário uma boa formação dos professores para que possam receber e desenvolver atividades significativas para todos os alunos, incluindo o aluno surdo, e outras deficiências, pois somente o uso da Libras não garante o seu aprendizado. Para ele, se o "[...] uso de uma língua bastasse para aprender, as pessoas ouvintes não teriam problemas de aproveitamento escolar, já que entram na escola com uma língua oral desenvolvida" (DAMÁZIO, 2007, p. 15).

Neste aspecto, não podemos, enquanto professores de Matemática, encarregar o intérprete de Libras da formação do aluno surdo, pois esta não é a função deste profissional, tornando-nos acomodados no processo de ensino e aprendizagem do mesmo, por haver alguém que se comunique mais com ele. Aliás, áreas da Educação Matemática tem dedicado estudos a favor de um ensino da Matemática, no âmbito escolar, que promova a construção do conhecimento matemático, bem como tem trazido reflexões e contribuições para a formação docente em uma perspectiva inclusiva, oportunizando, de forma igualitária, um ensino de ótima qualidade para todos os alunos.

Com relação a isso, Lucion (2015, p. 49) pontua que: “A qualidade de ensino tende a ser um desafio, principalmente quando ocorre a inclusão de alunos com deficiência, visto como, por vezes, é ministrado o ensino para esse alunado e devido às peculiaridades que eles apresentam em relação ao processo de aprendizagem”. Por se tratar de um desafio, é imprescindível a constante formação do docente, para uma boa atuação em uma sala inclusiva, sempre buscando novos conhecimentos e o aperfeiçoamento em novos métodos, capazes de atender as especificidades dos alunos.

Assim, na perspectiva da formação do professor de Matemática, Lucion (2015, p. 50) menciona que

[...] a formação do professor que ensina Matemática no contexto de inclusão abrange os conhecimentos construídos antes do ingresso no espaço acadêmico da universidade e prossegue durante a vida profissional. Engloba um movimento de constituição influenciado pela trajetória de vida, pelas experiências consideradas significativas.

Da mesma forma, Moreira (2016, p. 12), sobre o papel do professor no ensino e aprendizagem da Matemática para alunos com deficiências, argumenta que 
[...] é importante que os professores que ensinam Matemática tenham ao seu alcance material didático, ou instrucional, apropriado e de qualidade, com apelo tátil, visual e auditivo de modo a atender todos os alunos com NEE, levando-os à construção de conceitos matemáticos, seja por meio de utilização de jogos didáticos, seja por meio de atividades lúdicas, para mobilizarem todos os alunos da sala de aula rumo a uma aprendizagem matemática mais significativa [...].

Ainda, em relação aos materiais didáticos voltados para o ensino de alunos surdos, Moreira (2016, p. 13) coloca que estes podem ser usados tanto para os ouvintes quanto para os surdos, “[...] modificando apenas a abordagem e a metodologia, que devem ser adequadas às especificidades de cada grupo de estudantes [...]”. Logo, o aluno surdo e o ouvinte poderão também interagir, buscando meios de se comunicar para melhor realização das atividades propostas pelo professor. Além disso, é preciso considerar a pessoa surda "[...] de forma igualitária aos semelhantes, não sendo necessário atribuir nenhum adjetivo a eles, seja bom ou ruim, "nem herói, nem vítima, nem Deus, nem demônio, nem melhor, nem pior, nem superhomem, nem animal. Pessoa"”' (AMARAL, 1994, p. 15 apud MOREIRA, 2016, p. 750).

É importante considerarmos algumas orientações sobre como lidar com alunos surdos no âmbito de uma sala de aula, como utilização de recursos didáticos visuais, favorecendo a apropriação do conhecimento pela visão. Ressaltamos, também, com base no documento do Núcleo de Políticas de Inclusão (NUPI) ${ }^{5}$, que pequenas ações podem fazer diferença na aprendizagem do aluno surdo em sala de aula: fornecer ao interprete de Libras o plano do curso e materiais impressos a serem utilizados na disciplina; evitar a explanação do conteúdo enquanto estiver de costas ou escrevendo na lousa; comunicar as instruções gerais de trabalhos acadêmicos por escrito; utilizar materiais concretos, visuais para o desenvolvimento da aula; dentre outros.

Entendemos que estas orientações são necessárias na educação escolar, pois elas propiciam o desenvolvimento das funções psicológicas superiores, isto é, as funções que caracterizam o comportamento consciente do indivíduo, no caso, o aluno surdo, e que se estruturam nas relações sociais. Vigotsky e Luria (1996, p. 226) apresentam uma discussão a respeito do comportamento humano e o seu desenvolvimento por meio de técnicas externas e internas ao indivíduo. Sobre as técnicas externas, os pesquisadores dizem que um recurso ou dispositivo artificial podem compensar deficiências físicas e alguns defeitos psicológicos, contudo nos alertam sobre a compensação ocorrer "[...] não só por métodos externos, mas também pela organização e orientação do caráter de toda personalidade. Não podemos olhar

\footnotetext{
${ }^{5}$ Maiores informações em: https://www.ufrb.edu.br/nupi/images/documentos/Orientaes\%20para\%20pro fessores\%20de\%20estudantes\%20surdos.pdf. Acessado em: 06 mai. 2019.
} 
um defeito como algo estático e permanente". Esta organização e orientação da personalidade do indivíduo são formadas no âmbito das relações sociais com a utilização da linguagem e dos recursos auxiliares artificiais, como as hoje denominadas tecnologias assistivas.

Desta maneira, sob a perspectiva histórico-cultural, a qual compreende que é por meio das interações sociais que há o desenvolvimento das funções superiores do sujeito, por exemplo, o ensino para surdos deve atender suas características e potencializar suas especificidades, sendo, portanto, necessárias estratégias alternativas "[...] e recursos pedagógicos para a inclusão, sobretudo através da acessibilidade e da tecnologia assistiva" (LÜBECK; KLAUS; MOURA, 2018, p. 86).

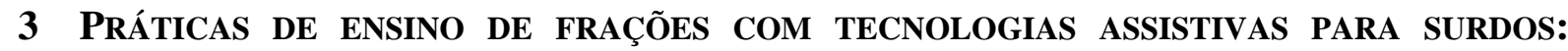 IMPLEMENTAÇÃO DE TAREFAS COM ACADÊMICOS DE LICENCIATURA EM MATEMÁTICA}

A Matemática é tomada como a disciplina em que os alunos mais apresentam dificuldades. E ao falar do tema frações, ela se torna ainda mais temida pelos alunos, pela complexidade de seus conceitos e falta compreensão, sobretudo quando o professor não recorre a práticas metodológicas diferenciadas, como tecnologias, jogos e materiais didáticopedagógicos para ensinar. Apresentar frações aos alunos de forma diferenciada da abordagem tradicional pode favorecer bastante o processo de aprendizagem. Prevê, Sheneckemberg e Munhoz (2014, p. 4) dizem que "a construção matemática dos números racionais é complexa, tendo a necessidade de se trabalhar com materiais concretos [...]", podendo esses ir desde software até tiras de cartolinas, material dourado, tampas de garrafas, jogos etc.

Desta forma, procuramos desenvolver uma proposta de ensino de frações para surdos para ser implementada no $3^{\circ}$ ano do Curso de Licenciatura em Matemática, amparada por algumas tecnologias adaptadas, ou tecnologias assistivas, para averiguar como esses alunos, futuros professores, lidam com essas tecnologias no ensino de frações. Esclarecendo, com base em Brasil (2009, p. 1), tecnologias assistivas dizem respeito

[...] à pesquisa, fabricação, uso de equipamentos, recursos ou estratégias utilizadas
para potencializar as habilidades funcionais das pessoas com deficiência. A aplicação
de Tecnologia Assistiva abrange todas as ordens do desenvolvimento humano, desde
as tarefas básicas de autocuidado até o desempenho de atividades profissionais.

Alguns dos recursos aproveitados na proposta, tais como o multimídia, os círculos fracionários e jogos, são encontrados facilmente no ambiente escolar, e ao serem adaptados, conforme a revisão de literatura que realizamos, tornam-se bons materiais para apresentar a Matemática ao aluno surdo. O projetor multimídia, por exemplo, permite uma aproximação 
maior do aluno com o que está sendo transmitindo, porque, as apresentações se tornam mais interessantes, fazendo com que a atenção do aluno seja cativada. Pensando no aluno surdo, este recurso pode ser um grande aliado, pois, por meio dessa tecnologia, as imagens e situações apresentadas se tornam mais visuais, indo além da tradução simultânea realizada pelo TILS. Seu uso em uma sala de aula faz com que o professor, ao preparar sua aula, repense a maneira de transmissão dos problemas propostos aos alunos, trazendo mais imagens e associações.

Na proposta, utilizamos o multimídia para apresentarmos os slides tendo por intenção promover uma conscientização a respeito deste artefato no ensino dos surdos. Por meio da apresentação em slides, mostramos para os alunos do $3^{\circ}$ ano do curso de Licenciatura em Matemática um pouco da trajetória e da luta do surdo para ocupar o seu espaço na sociedade, até a oficialização e reconhecimento da Libras como a sua língua materna. Durante esse momento, questões relacionadas sobre a prática do oralismo foram feitas, e dessas percebemos tristezas de alguns acadêmicos com relação a imposição da fala para o surdo e o quanto o surdo não era respeitado em suas particularidades. Ressaltamos a importância de fazer uma apresentação que favoreça e estimule o sentido visual, evitando fundos escuros e muito texto escrito, mas destacando as imagens para a associação das ideias expostas.

Em seguida, abordamos com os acadêmicos o uso de recursos manipuláveis e de muita cor para envolver a atenção do aluno surdo no processo de ensino da Matemática. Também enfatizamos o papel do professor e o do TILS no processo de aprendizagem, deixando claro que quem deve sempre buscar meios para que seu aluno se aproprie do conhecimento matemático é o professor.

Colocamos para os acadêmicos do curso de Matemática que o conteúdo a ser trabalhado no decorrer da implementação era o ensino de frações, e falamos com eles sobre a ideia de frações, porém as atividades realizadas na implementação enfatizaram a noção parte de um todo, pela justificativa de que, geralmente, quando se introduz este conteúdo, “[...] vemos o significado parte-todo como o mais abordado nos livros didáticos, onde as crianças contam o total de partes e, então, é colocado esse número no denominador e as partes pintadas no numerador" (ALVES; MARTENS, 2011, p. 8).

Com relação à aplicação das atividades da proposta educativa, um dos materiais que utilizamos foram os discos, ou círculos fracionários, recurso de fácil acesso nas escolas, e que auxilia na visualização e representação gráfica de uma fração. A respeito disto, Santos (2014, p. 28) argumenta que 
Além do uso para abordar o conceito de fração, os discos se apresentam como um bom recurso para comparar números fracionários, encontrar frações equivalentes, também são de grande importância nas operações de adição e subtração de frações. Seu principal objetivo é fazer com que o aluno possa construir o conceito e saber identificar as frações, auxiliando também na escrita e na leitura das mesmas.

Com o uso dos círculos fracionários podemos avançar no desenvolvimento do conteúdo de frações, de acordo com a criatividade do professor e sob uma perspectiva pedagógica mais visual, que segundo Ducatti e Villwock (2016), isto favorece para a cooperação e interação entre os alunos ouvintes e surdos. Os círculos são um recurso didático que propicia o visual e o manipulativo, oportunizando a descoberta e formalização de conceitos referentes ao assunto de fração. Os acadêmicos do curso, na sua grande maioria, não conheciam esse material, e ficaram encantados com a mobilidade do mesmo, inclusive quando inserido em outras atividades, como na aplicação de jogos.

Ao fim das atividades com o círculo fracionário, foi solicitado aos acadêmicos que se dividissem em grupos de 4 pessoas para que jogassem o Dominó das Frações (Figura 1), um jogo que pode ser encontrado nas escolas e que é visto como um recurso capaz de explorar o conceito de fração, a representação fracionária, a leitura e escrita da mesma. O jogo segue as regras básicas de um dominó comum, portanto, não houveram dúvidas dos alunos quanto a isto, porém com relação às partes pintadas das figuras do Dominó, uma aluna manifestou no grupo uma confusão em saber qual das partes, a colorida e a não colorida, pintada na figura, era o numerador e o denominador, levando-nos a deduzir que ela pudesse apresentar algum problema conceitual.

Góes (2002, p. 105-106), baseada em Vigotsky, explica que:

O desenvolvimento da criança com deficiência é, ao mesmo tempo, igual e diferente ao da criança normal. As leis de desenvolvimento são as mesmas, assim como as metas educacionais. Por outro lado, para se desenvolver e se educar, ela precisa de certas condições peculiares [...]. Logo, caminhos alternativos e recursos especiais não são peças conceituais secundárias na compreensão desse desenvolvimento.

Nesta perspectiva, é preciso recorrer a recursos especiais, que requer adaptação, para que os alunos que apresentam dificuldades possam adquirir os conhecimentos na escola, e a tecnologia assistiva auxilia nesse processo. Portanto, uma das alternativas que usamos naquele momento foi, juntamente com a aluna, refletir e discutir sobre as atividades anteriores realizadas, bem como aplicar o jogo da Memória com Frações, que tem por objetivo fazer com que o jogador encaixe a imagem (representação em desenho) com a fração. 


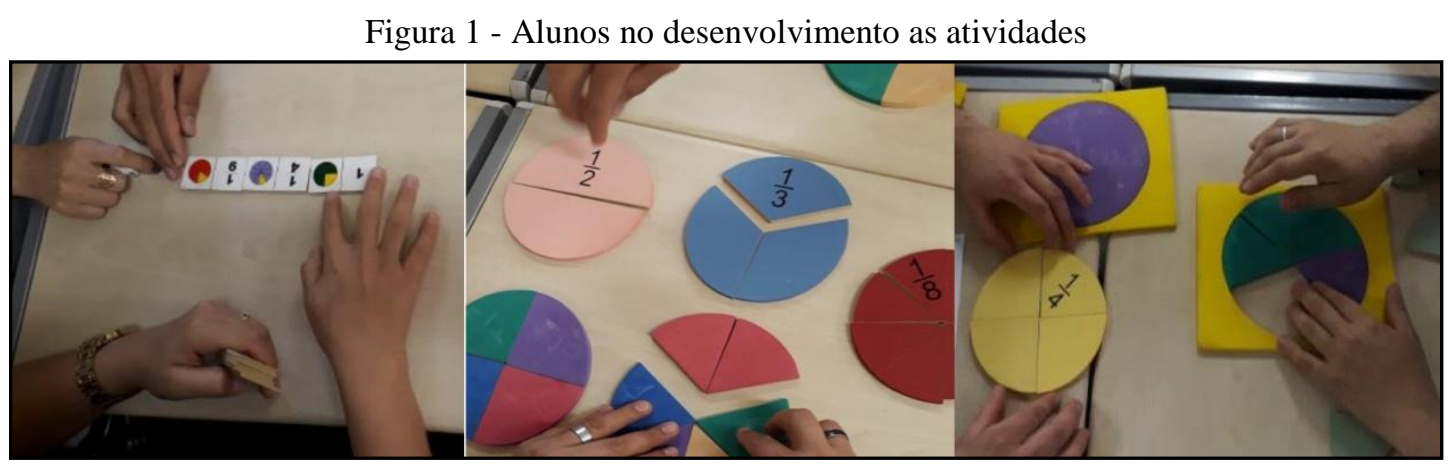

Fonte: Autores, 2018.

Quanto aos jogos, Grando (2004, p.18) aponta como sendo um meio que "[...] propicia um ambiente favorável ao interesse da criança, não apenas pelos objetos que o constituem, mas também pelo desafio das regras impostas por uma situação imaginária que, por sua vez, pode ser considerado como meio do pensamento abstrato". Além do mais, Pott e Tancredi (2017, p.14) colocam que, “[...] para aprender Matemática dando significado aos seus conteúdos, estabelecer relações é essencial"'.

Ao jogar o Dominó das Frações, por exemplo, o aluno é levado a exercitar suas habilidades mentais e a se relacionar. Neste jogo, os alunos associam a representação gráfica e numérica das frações, bem como praticam a leitura das frações. Para os surdos, o jogo pode se tornar um grande aliado na sua formação, devido a sua forma lúdica e visual, podendo trazer maior significado à aprendizagem. Nesta ideia, aliás, o jogo da Memória com Frações favorece a assimilação das representações gráficas e a linguagem matemática escrita, tendo como diferencial o exercício da memória e atenção do aluno, pois o mesmo precisa se manter atento às peças que já foram viradas.

Ressaltamos, com base em Sales (2013), que afirma que os surdos possuem os sentidos visuais mais acurados do que os ouvintes, porém o pesquisador argumenta que tal feito não é algo natural para eles, é preciso desenvolver a visualidade do surdo, por isso compreendemos a necessidade e a importância de atividades como as apresentadas neste artigo serem aplicadas pelos professores nas salas de aulas, seja na Educação Básica ou Superior.

Com base na pesquisa de Costa (2017), atividades como o Dominó e Memória com Frações, e outras, podem facilitar a compreensão do conteúdo matemático para o aluno surdo, visto que estes, e outros jogos, desenvolvem o uso constante do sentido visual, e isto tende a torná-lo mais observador e ter mais facilidade para encontrar os pares de figuras relacionadas ao conceito de fração apresentada nesta pesquisa. Ainda, segundo a autora, além da necessidade de o professor dominar o conteúdo a ser ensinado para o surdo, é importante que este 
profissional, acerca da prática docente, leve em consideração o contexto sociocultural no qual os alunos estão inseridos, pois estes saberes que o professor possui em relação ao contexto poderá auxiliá-lo em sua prática docente e mobilizar "[...] saberes pedagógicos para a construção de práticas inclusivas" (COSTA, 2017, p. 118).

O jogo Trilha das Frações (Figuras 2 e 3), adaptado para o estudo de frações, possui regras básicas de um jogo de trilha e um tabuleiro com escritas em libras, permitindo o estudo desta língua e a comunicação entre o aluno ouvinte e o aluno surdo. De acordo com Nascimento, Araújo e Viana (2016), o jogo pode favorecer o desenvolvimento do raciocínio lógico, a resolução de operações aritméticas com frações e, principalmente, potencializar habilidades funcionais do aluno surdo.

Figura 2 - Trilha das frações

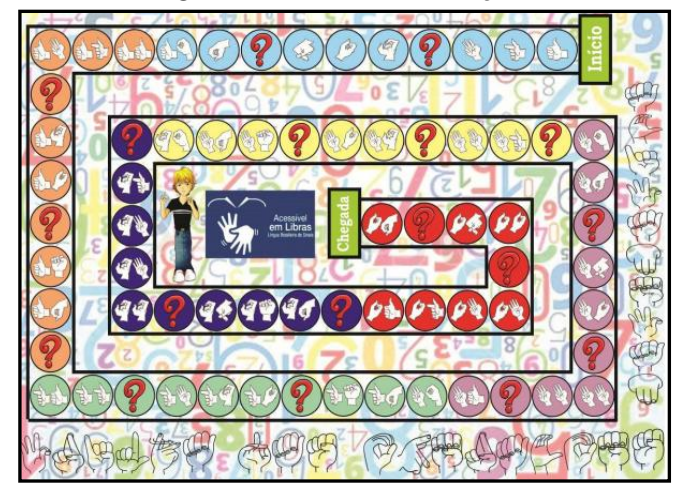

Fonte: Nascimento, Araújo e Viana (2016).
Figura 3 - Jogando a Trilha das frações

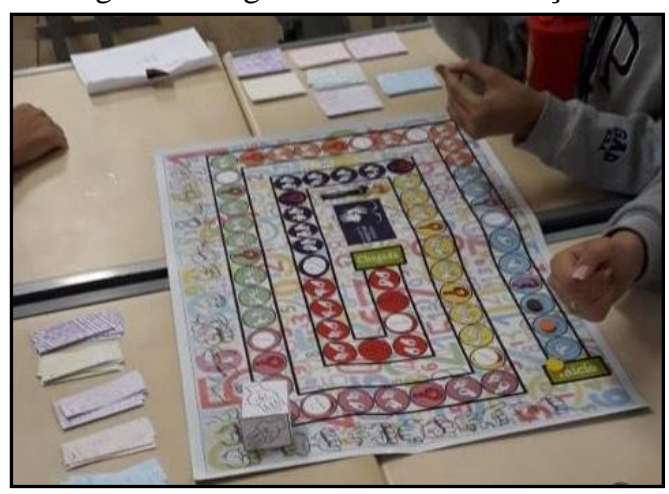

Fonte: Autores (2018).

Percebemos durante o jogo um envolvimento espetacular dos alunos do curso de Matemática, pois todos jogaram, e para incentivar a prática da Língua de Sinais, visto que todos os participantes já haviam cursado a disciplina de Libras, foi pedido que durante o jogo as respostas às operações fossem feitas utilizando a Libras.

Após o término dessas atividades, foi projetado pelo multimídia à turma um desafio matemático (Figura 4): "Se um tijolo pesa $1 \mathrm{~kg}$ mais meio tijolo, então quanto pesa um tijolo e meio? ". O desafio, além de estimular o raciocínio dos alunos, tinha o propósito instigar a interpretação e mostrar aos acadêmicos de Matemática uma forma de apresentar problemas matemáticos para alunos surdos, isto é, enfatizando os aspectos bem visuais. 


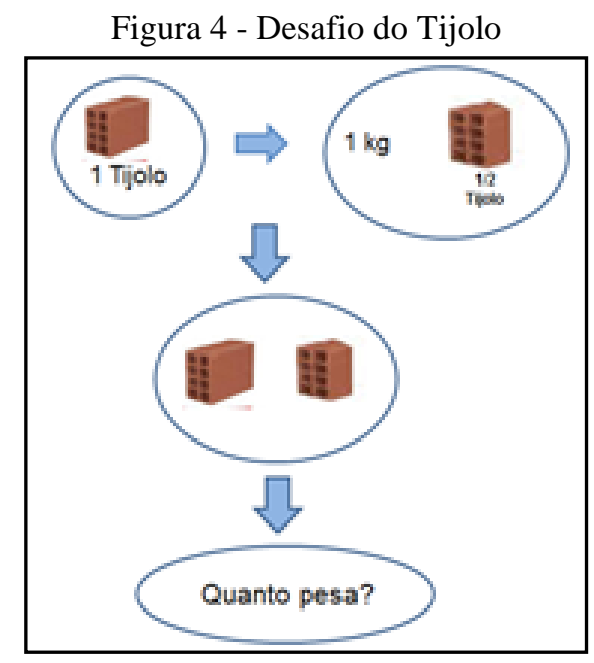

Fonte: Autores, 2018.

Para Morás e Klaus (2018), “[...] a surdez é uma experiência visual [...]. E isso significa que todos os mecanismos de processamento da informação, e todas as formas de compreender o universo em seu entorno, se constroem como experiência visual" (SKLIAR, 1998, p. 28 apud MORÁS; KLAUS, 2018, p. 305). Ao apresentarmos o problema na forma de esquemas, notamos a surpresa dos acadêmicos à essa abordagem, porém, todos disseram ser interessante e necessário, após alguns momentos de discussão e reflexão.

Ao término da aplicação da proposta, foi entregue aos alunos um questionário avaliativo contendo três perguntas, tendo como finalidade conhecer as impressões dos acadêmicos. Sobre a pergunta "O que achou da proposta didática implementada?", a maioria dos alunos avaliou a proposta como criativa, interessante e que poderá favorecer a interação social entre os alunos ouvintes e os alunos com surdez. Um escreveu no seu registro que o jogo é um importante instrumento para a aprendizagem, dizendo: “Achei interessante, pois os jogos auxiliam na aprendizagem da Matemática”.

Referente à questão “O que mudaria na proposta didática implementada?”, cinco dos onze alunos relataram não mudar nada na proposta apresentada para eles. No entanto, quatro alunos relataram ter tido dificuldades ao assimilar as cores do jogo, por se tratarem de cores parecidas nas cartas. Em especial, um dos alunos apontou em seu registro escrito ter sentido falta de mais dificuldades no caminhar da trilha, isto é, de desafios durante o jogo, dizendo: "As cores, colocaria 'volte ao início' mais vezes e mudaria as recompensas”. Houve também, por partes dos alunos, a sugestão de inserir a Libras em mais momentos da proposta, o que nos leva a inferir que esse aluno tenha a compreensão da importância do ensino para os alunos surdos ocorrer de modo bilíngue. 
A respeito da pergunta "Para você, a proposta didática implementada favorece o desenvolvimento de uma prática inclusiva nas aulas de Matemática?", os acadêmicos do curso de Licenciatura em Matemática da UNIOESTE, campus de Foz do Iguaçu/PR disserem que sim, apontando, principalmente, que o jogo adaptado, e a ludicidade do mesmo, pode contribuir em muito na aprendizagem de todos os alunos no que se refere a frações. Um disse: "Com certeza. Pois favorece o compreendimento da matéria, bem como os alunos com condições especiais, e os demais sem necessidades especiais". Podemos inferir pelo registro desse aluno, apesar do equívoco na língua portuguesa, que a implementação favoreceu a compreensão do assunto trabalhado, bem como considerou as particularidades dos surdos, enfatizando a promoção da aprendizagem dos alunos ouvintes, quando se refere aos "[...] demais sem necessidades especiais".

Concluímos, também, que tais argumentos podem ser reflexos dos ensinamentos e das discussões que esses alunos tiveram enquanto cursavam as disciplinas de Libras e Educação Especial e Inclusão Escolar promovidas pela colegiado de Matemática, mostrando para nós que, apesar dos alunos ainda não atuarem como professores e não terem tido experiências com os surdos, o que não anula a importância e necessidade de vivenciarem experiências com essas pessoas, tais reflexões teóricas sobre as práticas docentes em uma perspectiva inclusiva já se fazem imprescindíveis na formação inicial.

\section{CONSIDERAÇÕES FINAIS}

No decorrer da implementação, averiguamos, por meio dela, que os acadêmicos do $3^{\circ}$ ano do curso de Licenciatura em Matemática, possuem alguns saberes de como trabalhar tecnologias assistivas com alunos surdos, decorrência das disciplinas cursadas, tais como Libras e Educação Especial e Inclusão Escolar. A saber, a disciplina de Libras é ministrada por uma professora surda e a outra é ministrada por uma professora integrante do Programa de Educação Especial (PEE) ${ }^{6}$ da UNIOESTE, o qual tem, dentre seus objetivos, promover ações relativas às pessoas com necessidades especiais. Apesar disto, das análises dos registros escritos, percebemos que alguns acadêmicos do curso de Licenciatura em Matemática apresentam problemas de entendimento e de como manusear os círculos fracionais, devido a não compreensão do significado de fração, um problema quiçá conceitual, no caso, dificuldade em relacionar a função do numerador e do denominador da fração com suas representações na forma de desenhos.

\footnotetext{
${ }^{6}$ Maiores informações em: http://cac-php.unioeste.br/projetos/pee/m_gra/pee.php. Acessado em: 06 mai. 2019. 
Com relação às tecnologias assistivas utilizadas na implementação da proposta, os alunos apontaram em seus registros escritos como sendo recursos promissores para o ensino de frações para alunos surdos, demonstrando em alguns momentos da aula, admiração com determinadas abordagens que não conheciam para trabalhar problemas matemáticos com essa deficiência, como a apresentada no desafio do tijolo, bem como alegaram a necessidade de algumas mudanças no planejamento das atividades, no intuito de trazer melhorias, como propiciar a comunicação da Libras em mais momentos das aulas e colocar mais casas com desafios no tabuleiro do jogo Trilha de Frações.

Estes olhares advindos dos acadêmicos reafirmam as ideias trazidas em Costa (2017), a qual aponta a necessidade de domínio que o professor deve ter do conteúdo para ensinar todos os alunos, especialmente para os surdos, em foco aqui, bem como a importância desses acadêmicos vivenciarem experiências num contexto em que alunos ouvintes e surdos estão inseridos, visto que os saberes constituídos desses momentos podem proporcionar no planejamento pedagógico saberes que visam práticas de ensino inclusivas. Em vista disto, compreendemos que projetos de ensino, pesquisa e extensão promovidos pela universidade, desde a fase de formação inicial docente, tanto de aspecto teórico quanto prático, tornam-se, a nosso ver, caminhos propícios para a práxis docente no que diz respeito às temáticas apresentadas no decorrer deste estudo.

De modo geral, os resultados obtidos na aplicação da proposta apresentam que, por meio do uso de tecnologias assistivas para o ensino de frações, houveram avanços significativos na aprendizagem dos acadêmicos do $3^{\circ}$ ano com relação às frações e na temática de inclusão escolar e educação especial, e os apontamentos apresentados por esses alunos durante o desenvolvimento das atividades foram de grande importância para a pesquisa, pois propiciaram olhares sobre questões do processo de inclusão escolar, do acesso ao ensino da Matemática para surdos, contribuindo, assim, para a formação inicial desses acadêmicos, que em breve serão professores.

Cabe destacarmos o uso das tecnologias assistivas como apoio didático, em que o professor pode valer-se para que os conteúdos científicos sejam internalizados pelos surdos. No entanto, as tecnologias assistivas não minimizam a função do professor como mediador do conhecimento e do intérprete educacional que faz a mediação linguística nesse contexto. Por fim, sabemos o quão é desafiador promover aulas na perspectiva inclusiva no universo das salas regulares da Educação Básica, em vista dos inúmeros fatores que acolá atuam, como a pluralidade de pensamentos e a diversidade sociocultural, e do próprio sistema educativo não 
ter sido pensando para tal, todavia, apesar das dificuldades, cabe também a nós professores fazer uma diferença, que a nosso ver nos incumbe a iniciarmos uma formação docente crítica e reflexiva dos assuntos voltados à inclusão nas salas de aula da universidade durante o processo de qualificação inicial para a docência.

\section{REFERÊNCIAS}

ALVES, Denis Rogério Sanches; MARTENS, Adam Santos. Desafios para a Construção do Conhecimento de Frações nas Séries Intermediárias do Ensino Fundamental. 2011. Disponível em: educere.bruc.com.br/CD2011/pdf/6413 3640.pdf. Acessado em: 20 out. 2018.

BARDIN, Laurence. Análise de Conteúdo. São Paulo: Edições 70, 2011.

BAQUERO, Marcello. Democracia Formal, Cultura Política Informal e Capital Social no Brasil. Opinião Pública, Campinas, v. 14, n. 2, p. 380-413, nov. 2008. Disponível em: http://www.scielo.br/pdf/op/v14n2/05.pdf. Acessado em: 21 jul. 2018.

BISOL, Cláudia; SPERB, Tania Mara. Discursos sobre a Surdez: Deficiência, Diferença, Singularidade e Construção de Sentido. Psicologia: Teoria e Pesquisa, [S.L], v. 26, n. 1, p. 713, jan./mar. 2010. Disponível em: http://www.scielo.br/pdf/ptp/v26n1/a02v26n1.pdf. Acessado em: 12 jul. 2018.

BRASIL. Lei 9.394 de 20 de dezembro 1996. Lei de Diretrizes e Bases da Educação Nacional. Estabelece as Diretrizes e Bases da Educação Nacional. Disponível em: http://www.planalto.gov.br/ccivil_03/Leis/19394.htm. Acessado em: 16 jun. 2018.

BRASIL. Ministério da Educação. Diretrizes Nacionais para a Educação Especial na Educação Básica 2001. Secretaria de Educação Especial/MEC. Disponível em: http://portal.mec.gov.br/seesp/arquivos/pdf/diretrizes.pdf. Acesso em: 13 jul. 2018.

BRASIL. Lei No 10.436 de 24 de abril de 2002. Dispõe sobre a Língua Brasileira de Sinais - Libras, e dá outras providências. Disponível em: http://www.planalto.gov.br/ccivil_03/leis/2002/110436.htm. Acessado em: 22 ago.2018.

BRASIL. Subsecretaria Nacional de Promoção dos Direitos da Pessoa com Deficiência. Comitê de Ajudas Técnicas Tecnologia Assistiva. Brasília: CORDE, 2009. Disponível em: https://www.pessoacomdeficiencia.gov.br/app/sites/default/files/publicacoes/livro-tecnologiaassistiva.pdf. Acessado em: 20 out. 2018.

BRASIL. Lei 12.319 de 01 de setembro de 2010. Lei que Regulamenta a Profissão do Tradutor Intérprete da Língua de Sinais Brasileira - LIBRAS. Disponível em: http://www.planalto.gov.br/ccivil_03/_ato2007-2010/2010/lei/112319.htm. Acessado em: 21 jul. 2018.

BRASIL. Lei 13.146 de 6 de julho de 2015. Lei Brasileira de Inclusão da Pessoa com Deficiência. Disponível em: http://www.planalto.gov.br/ccivil_03/_ato20152018/2015/lei/113146.htm. Acessado em: 21 jul. 2018. 
COSTA, Viviane Cristiane. Saberes Docentes e Educação Matemática Inclusiva: investigando o potencial de um curso de extensão voltado para o ensino de Matemática para surdos. 164 f. Dissertação (Mestrado Profissional em Educação Matemática) - Universidade Federal de Ouro Preto, Ouro Preto, 2017. Disponível em:

https://repositorio.ufsc.br/xmlui/bitstream/handle/123456789/190928/COSTA\%20Viviane\%2 0Cristiane \%202017\%20\%28disserta\%C3\%A7\%C3\%A30\%29\%20UFOP.pdf?sequence=1\&is Allowed=y. Acessado em: 06mai. 2019.

DAMÁZIO, Mirlene Ferreira Macedo. Atendimento Educacional Especializado: pessoa com Surdez. Curitiba: Cromos. 2007. Disponível em:

http://portal.mec.gov.br/seesp/arquivos/pdf/aee_da.pdf. Acessado em: 13 jul. 2018.

DUCATTI, Claudia Vicente; VILLWOCK, Rosangela. Práticas pedagógicas direcionadas à inclusão do estudante surdo. In: PARANÁ. Secretaria de Estado da Educação.

Superintendência de Educação. O professor PDE e os desafios da escola pública paranaense, 2014. Curitiba: SEED/PR., 2016. V.2 (Cadernos PDE). Disponível em: http://www.diaadiaeducacao.pr.gov.br/portals/cadernospde/pdebusca/producoes_pde/2014/20 14_unioeste_mat_artigo_claudia_vicente.pdf. Acessado em: 06mai. 2019.

GÓES, M. C. R. Relações entre Desenvolvimento Humano, Deficiência e Educação: contribuições da abordagem Histórico-Cultural. In: OLIVEIRA. M.K.; REGO, T.C.; SOUZA, D.T. R. (Org.). Psicologia, Educação e as Temáticas da Vida Contemporânea. São Paulo: Moderna, 2002. p. 95-114.

GRANDO, Regina Célia. O Jogo e a Matemática no Contexto da Sala de Aula. São Paulo: Paulus, 2004.

LÜBECK, Marcos; KLAUS, Vanessa Lucena Camargo de Almeida; MOURA, Elmha Coelho Martins. Novas Perspectivas de Atuação: os desafios para o futuro. In: LÜBECK, Kelly Roberta Mazzutti (Org.). História, Educação e Docência: 20 anos do curso de Licenciatura em Matemática da Unioeste/Foz do Iguaçu. Curitiba: CRV, 2018, p. 77-100.

LUCION, Paula. A Organização do Ensino de Matemática no Contexto de Inclusão. 2015. 183 f. Dissertação (Mestrado em Educação) - Universidade Federal de Santa Maria, Santa Maria, 2015. Disponível em:

https://repositorio.ufsm.br/bitstream/handle/1/7234/LUCION\%2C\%20PAULA.pdf?sequence =1\&isAllowed=y. Acessado em: 20 out. 2018.

MENDES, Enicéia Gonçalves. Perspectivas para a construção da escola inclusiva no Brasil. In: PALHARES, Marina Silveira; MARINS, Simone Cristina Fanhani. (Orgs.). Escola inclusiva. São Paulo: EDUFSCAR, 2002. p. 61-86.

MORÁS, Nadjanara Ana Basso; KLAUS, Vanessa Lucena Camargo de Almeida. Estrategias y Procedimientos de Alumnos Sordos en la Resolución de Problemas del Campo Conceptual Aditivo. Revista Paradigma, v. XXXIX, n. 1; jun. 2018, p. 301-318. Disponível em: http://revistas.upel.edu.ve/index.php/paradigma/article/view/6791. Acessado em: 18 out. 2018.

MOREIRA, Geraldo Eustáquio. O Ensino de Matemática para Alunos surdos: dentro e fora do texto em contexto. Educ. Matem. Pesq., São Paulo, v. 18, n. 2, p. 741-757, jul. 2016. 
Disponível em: https://revistas.pucsp.br/index.php/emp/article/viewFile/23486/pdf. Acessado em: 12 jul. 2018.

NASCIMENTO, Ayrton Matheus da Silva; ARAÚJO, Rafaela Germania Barbosa de; VIANA, Kilma da Silva Lima. Trilha das Operações Matemáticas em Libras: uma proposta didática. 2016. Disponível em:

https://editorarealize.com.br/revistas/cintedi/trabalhos/TRABALHO_EV060_MD1_SA7_ID4 160_23102016231317.pdf. Acessado em: 21 out. 2018.

PARANÁ. Departamento de Educação Básica. Organização do Trabalho pedagógico especializado na rede pública estadual de ensino. 2014. Disponível em:

http://www.gestaoescolar.diaadia.pr.gov.br/arquivos/File/sem_pedagogica/julho_2014/anexo7 .pdf.

POTT, Anelise Belão; TANCREDI, Regina Maria S. Puccinelli. Os Jogos no Ensino de Matemática: possibilidades de dinamização das práticas pedagógicas. 2017. Disponível em: www.portaldosprofessores.ufscar.br/biblioteca/18/artigo_para_o_portal.doc. Acesso em: 20 out. 2018.

PREVÊ, Deison Teixeira; SHENECKEMBERG, Cleder Marcos; MUNHOZ, Regina Helena. Lúdico no Ensino de Frações. BOEM, Joinvile, v. 2, n. 2, p. 88-99, jul. 2014.

SALES, Elielson Ribeiro de. A visualização no ensino da Matemática: uma experiência com alunos surdos. 2013. Tese (Doutorado em Educação Matemática) - Universidade Estadual Paulista, São Paulo, 2013. Disponível em:

https://repositorio.ufsc.br/bitstream/handle/123456789/188410/SALES,\%20Elielson\%20Ribe iro\%202013\%20(tese)\%20UNESP.pdf?sequence=1. Acesso em: 06mai. 2019.

SANTOS, Elias Souza dos. Comunidade surda: a questão das suas identidades. In: DÍAZ, F. et al. (Orgs.) Educação inclusiva, deficiência e contexto social: questões contemporâneas [online]. Salvador: EDUFBA, 2009, pp. 14-25. Disponível em:

http://books.scielo.org/id/rp6gk/pdf/diaz-9788523209285-02.pdf. Acessado em: 12 jul. 2018.

SANTOS, Maria José Batista De Souza. O Ensino e Aprendizagem das Frações Utilizando Materiais Concretos. 2014. Trabalho de Conclusão de Curso (Graduação em Licenciatura Plena em Matemática) - Universidade Estadual da Paraíba, Campina Grande, 2014.

Disponível em: http://dspace.bc.uepb.edu.br/jspui/bitstream/123456789/4290/1/PDF - Maria José Batista de Souza Santos.

http://dspace.bc.uepb.edu.br/jspui/bitstream/123456789/4290/1/PDF - Maria José Batista de Souza Santos.pdf. Acessado em: 20 out. 2018.

SCHRAM, Sandra Cristina; CARVALHO, Marco Antonio Batista. O Pensar Educação em Paulo Freire: para uma Pedagogia de mudanças. 2010. Disponível em:

http://www.diaadiaeducacao.pr.gov.br/portals/pde/arquivos/852-2. Acessado em: 16 jun. 2018.

VIANNA, Carlos Eduardo Souza. Evolução Histórica do Conceito de Educação e os Objetivos Constitucionais da Educação Brasileira. Janus Lorena, [S.L], n. 4, p. 129-138, jun./dez. 2006. Disponível em: 
http://www.publicacoes.fatea.br/index.php/janus/article/viewFile/41/44. Acessado em: 12 jul. 2018.

VIGNA, Mayre Barros Custódio. Inclusão (Jogos, Brincadeiras e Gincanas). São Paulo: DCL, 2010.

VIGOSTKY, Lev; LURIA, Alexander Romanovich. Estudo sobre a História do Comportamento: símios, o primitivo e a criança. Porto Alegre: Artes Médicas, 1996.

Recebido em: 5 de maio de 2019. Aprovado em: 21 de outubro de 2019. 